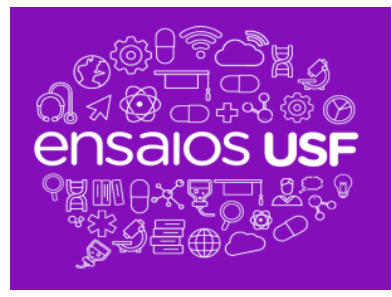

http://ensaios.usf.edu.br/

\title{
ESTUDO DA UTILIZAÇÃO DE FIBRAS CURTAS DE CELULOSE EM CERÂMICA VERMELHA
}

STUDY OF THE USE OF CELLULOSE SHORT FIBERS IN RED CERAMICS

\author{
TOBIAS, Mário Sérgio Meneguete ${ }^{1}$; VANNUCCHI, Paulo ${ }^{1}$; MARQUES, Elaine Cristina ${ }^{1}$ \\ ${ }^{1}$ Curso de Engenharia de Produção, Universidade São Francisco, Campus Itatiba - SP. \\ elainecrismarques@usf.edu.br
}

\begin{abstract}
RESUMO. Este trabalho tem o objetivo de analisar a possibilidade da inserção de até $10 \%$ de resíduo de celulose na matéria prima utilizada para produção de cerâmica vermelha. A celulose adquirida de Várzea Paulista foi misturada com argila vermelha obtida em Cordeirópolis até sua homogeneização para a produção de blocos feitos em molde de aço e prensados uniaxialmente a $25 \mathrm{MPa}$. Os blocos produzidos foram então submetidos a queima a $900{ }^{\circ} \mathrm{C}$. Após o resfriamento natural do material, as propriedades analisadas foram absorção de água, resistência mecânica e retração linear. Os testes conduzidos apresentaram absorção de água de $16,78 \%$ na argila pura, $17,9 \%$ para $3 \%$ de celulose, $19,64 \%$ para $5 \%$ de celulose e $25,26 \%$ para $10 \%$ de celulose. Valores de tensão máxima de $7,8 \mathrm{MPa}$ para a argila pura, 9,3 MPa para 3\% de celulose, 5,6 MPa para 5\% de celulose e 3,6 MPa para 10\% de celulose. Com as propriedades obtidas, conclui-se que a incorporação de $3 \%$ de resíduo de celulose na fabricação de produtos de cerâmica vermelha é uma alternativa sustentável para a utilização desse resíduo, que previamente seria descartado e não teria mais funcionalidade.
\end{abstract}

Palavras-chave: Resíduo de celulose, cerâmica vermelha, propriedades físicas, reciclagem.

ABSTRACT. This work has the objective of analyzing the possibility of insertion up to $10 \%$ of cellulose residue in the raw material used to produce red ceramics. The Pulp acquired in Varzea Paulista was mixed with red clay obtained in Cordeirópolis until homogenizing for the production of blocks made in steel molds and pressed uniaxially at $25 \mathrm{MPa}$. The pieces produced were submitted to a burning process at $900^{\circ} \mathrm{C}$. After natural cooling of the material the properties analyzed were water absorption, mechanical resistance and linear retraction. The tests conducted presented $16.78 \%$ water absorption on pure clay, $17.9 \%$ on $3 \%$ addition of cellulose, $19.64 \%$ on $5 \%$ of cellulose and $25.26 \%$ on $10 \%$ of cellulose. Values of maximum tension of 7.8 MPa for pure clay, 9.3 MPa for 3\% of cellulose, 5.6 MPa for 5\% of cellulose and 3.6 MPa for $10 \%$ of cellulose. Thus, it is concluded that the incorporation of $3 \%$ of cellulose residue in the manufacture of red ceramic products is a sustainable alternative for waste utilization, which would previously be discarded and have no further use.

Keywords: Cellulose residue, Red Ceramics, Physical properties, Recycling.

\section{INTRODUÇÃO}

A indústria de celulose brasileira tem um papel de destaque por sua produção e sua participação no mercado global. Esse cenário vem aumentando, como é o caso da empresa Fibria que há alguns anos vem investindo e no quarto trimestre do ano de 2016 teve um aumento de $21 \%$ com relação ao quarto trimestre de 2015 (FIBRIA, 2017).

Consequentemente, com todo esse aumento produtivo, a geração de resíduos também cresceu. Procuram-se maneiras de reaproveitar o material a ser descartado tornando-o útil e 
agregando valor a outros itens de diferentes estruturas. Uma solução desse problema pode ser a incorporação do resíduo na cerâmica vermelha, que por sua vez tem facilidade para ser produzida sendo misturada com outros materiais e manter-se dentro das normas de produção estipuladas pela NBR 15270-2 (2005).

Um estudo realizado por (RIBEIRO, 2010) indicou que a adição de até $10 \%$ de celulose na cerâmica e a queima utilizando uma temperatura variada entre $900{ }^{\circ} \mathrm{C}$ e $1000{ }^{\circ} \mathrm{C}$ produziu material com resultados aceitáveis para o mercado.

Para a realização deste estudo, testes com diferentes quantidades de resíduos de celulose adicionados à cerâmica vermelha foram realizados visando a manutenção das características estruturais.

Portanto, este estudo tem como objetivo a incorporação de fibras curtas de resíduo de celulose em cerâmica vermelha, de forma a caracterizar suas propriedades físicas, tais como, retração linear, resistência mecânica à flexão e absorção de água.

\section{Cerâmica Vermelha}

"O termo "cerâmica" vem da palavra grega keramikos, que significa "matéria queimada", indicando que as propriedades desejáveis desses materiais são atingidas normalmente por meio de um processo de tratamento térmico, a uma temperatura alta chamado queima." (CALLISTER Jr, 2016, p. 428).

A princípio os materiais cerâmicos eram diretamente relacionados as chamadas "cerâmicas tradicionais", se referindo a itens que tinham a argila como principal matériaprima. Com o passar do tempo e os avanços da área, o termo cerâmica ganhou um significado muito mais amplo, quando novas descobertas, com relação ao entendimento da natureza fundamental e dos fenômenos ocorridos, expôs as características únicas desse tipo de material (CALLISTER Jr., 2016).

O segmento da cerâmica vermelha é composto predominantemente pela produção de telhas, tijolos e blocos, utilizando basicamente a argila comum como principal fonte de matéria prima. Em 2013 estimou-se o consumo de aproximadamente 140 milhões de toneladas de argila para a produção de 68,3 bilhões de peças cerâmicas, considerando a massa média de 2,0 kg/peça (MME, 2017).

A estrutura empresarial apresenta-se bastante diversificada, contando majoritariamente por pequenos empreendimentos familiares. Segundo a ANICER, são 7400 pequenas unidades produtivas dessa indústria, sendo 600 empresas somente no estado de São Paulo, que geram cerca de 35 mil empregos diretos e 110 mil indiretos (MME, 2017).

A produção de cerâmica inicia-se na extração da argila, a céu aberto, que ocorre preferencialmente em meses de menor precipitação para que não haja diferença entre as camadas retiradas da matéria prima. Um responsável deve coletar amostra da primeira e da última carga para verificar possível mudança de material durante a extração (FEAM e FIEMG, 2013).

Em seguida tem-se a homogeneização (desintegração) da matéria prima, em que se usa água para dar plasticidade ao material, tornando possível a moldagem da peça no formato desejado (tijolo, bloco, telha). A mistura correta, adicionando água de maneira centralizada na máquina para que toda a massa possua a mesma umidade, é essencial para a conformidade do que será produzido. "Uma massa bem preparada pode gerar benefícios como: 35\% economia consumo de energia, acréscimo de $25 \%$ da produtividade, redução de cerca de $40 \%$ dos índices de deformação" (FEAM e FIEMG, 2013, p. 15).

O próximo passo é a laminação, responsável pelo direcionamento das partículas de argila e redução do tamanho do grão. Quanto mais fechado o laminador, melhor será o direcionamento das partículas. É recomendado um distanciamento de 2 a $3 \mathrm{~mm}$ para o último laminador. A qualidade da laminação determina a qualidade do acabamento do produto, visto 
que esse passo também reduz a granulometria da massa e pode levar a uma redução do consumo de energia (FEAM e FIEMG, 2013).

O próximo passo é o molde no formato desejado, seja ele o bloco (utilizado extrusora) ou a telha e o tijolo comum (utilizado prensa).

Após a peça moldada, ela passa ao processo de secagem, onde permanece de 12 a $24 \mathrm{~h}$ a uma temperatura de $100{ }^{\circ} \mathrm{C}$. Esse é o processo em que o material fica mais sensível a quebra, por não ter mais água para unificar a peça e ainda não possuir suas propriedades mecânicas finais, portanto é recomendado que a peça vá direto para o processo de queima (FEAM e FIEMG, 2013).

Durante o processo de queima a peça adquire suas propriedades finais, nesta fase, há perda de massa, sinterização dos grãos, e a formação da fase vítrea. O processo consiste em 3 passos: a elevação da temperatura, entre 800 e $1000^{\circ} \mathrm{C}$, a permanência por certo tempo na temperatura máxima, e o resfriamento controlado até menos de $200{ }^{\circ} \mathrm{C}$. Dependendo do tipo de produto final, e da tecnologia empregada, o processo total de queima pode variar de horas até dias. Após a finalização desse processo, a peça adquire suas propriedades finais (FEAM, FIEMG, 2013).

As etapas do processo são detalhadas conforme fluxograma presente na Figura 1.

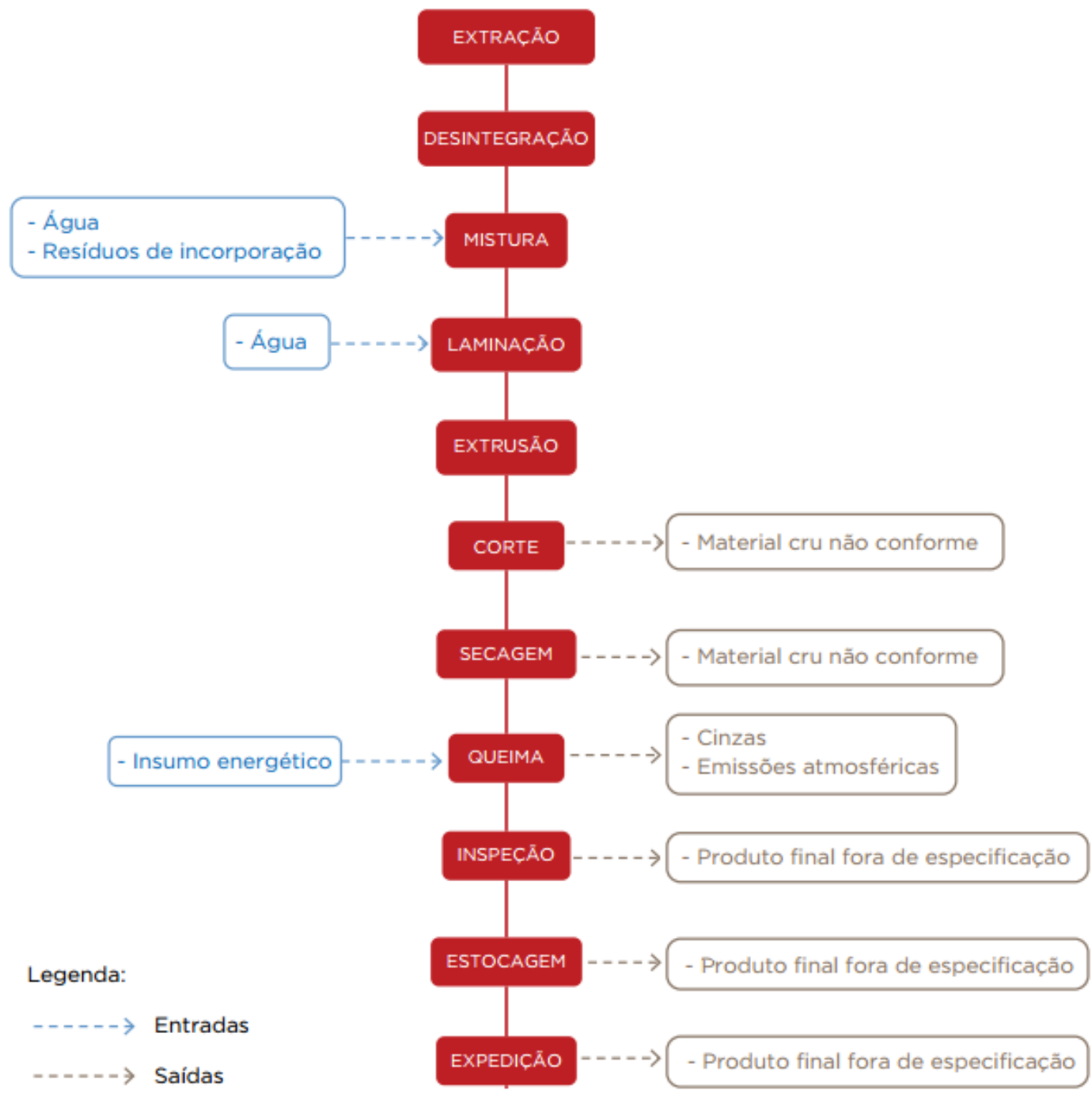

Figura 1 - Fluxograma do processo produtivo da cerâmica vermelha.

Fonte: FEAM e FIEMG (2013).

\section{Celulose}


O processo de reciclagem de papel vem acompanhando o crescimento das indústrias de celulose tanto na quantidade quanto nos avanços tecnológicos da área. Alguns casos atingiram um nível tão alto de reciclagem que afetou a qualidade do produto final, obtendo uma taxa de recuperação de $81 \%$ no ano de 2015 (ANAP, 2015).

A degradação de fibra de celulose ocorre a cada processo de reciclagem, atingindo um limite em que se torna impossível uma nova reutilização. Cada produto reciclado é utilizado em novos itens que não requerem uma alta qualidade. Assim, os papeis com fins sanitários, se abastecem de material reciclado proveniente dos papeis de imprimir e escrever (ANAP, 2015).

De acordo com a norma ABNT NBR 15483, existem 31 tipos de aparas definidas que podem ser agrupadas em 3 grandes grupos, sendo elas: as aparas marrons, oriundas de papeis de embalagens; as aparas brancas, originalmente utilizadas em papeis destinadas a impressão e as aparas de cartão, que são caixas e cartuchos produzidos para caixas de remédios, pastas de dentes, etc. (ANAP, 2015).

"Em relação à recuperação de papel, o Brasil figura entre os principais recicladores do mundo. Em 2015, estima-se que 4,6 milhões de toneladas retornaram ao processo produtivo, o que equivale a uma taxa de recuperação de $61 \%$ de todo o papel consumido passível de reciclagem.” (IBÁ, 2016, p. 69)

Analisando a Figura 2 é possível perceber o aumento de $11 \%$ entre 2010 e 2015, o que demonstra preocupação cada vez maior com a necessidade do reaproveitamento da celulose (IBÁ, 2016).
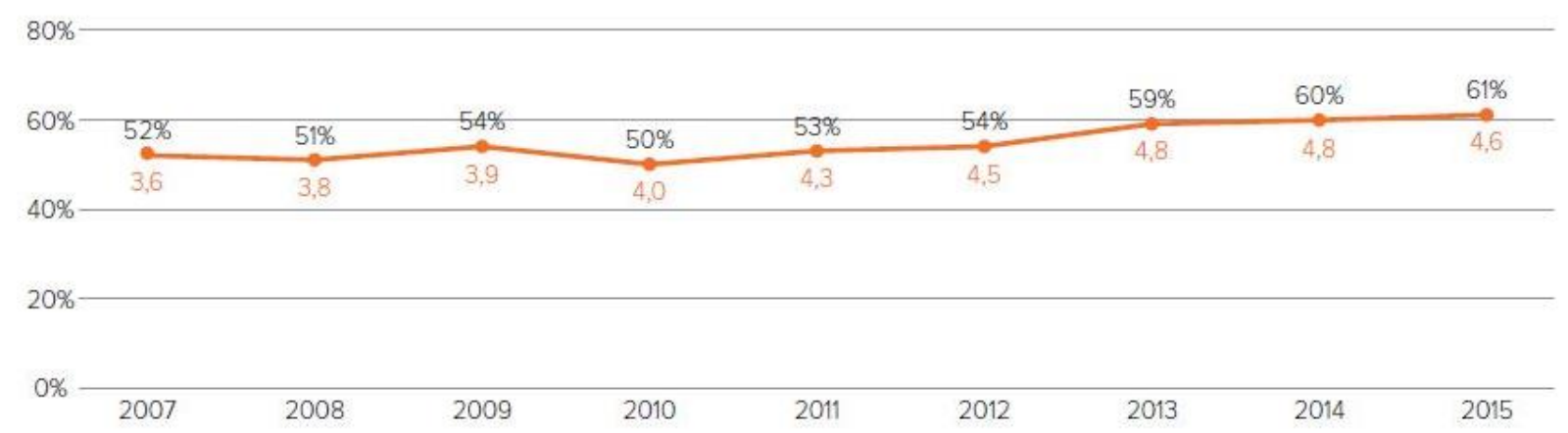

Figura 2 - Evolução da taxa de reciclagem de papéis no Brasil, 2007-2015.

Fonte: IBÁ (2016)

Diversas medidas já foram utilizadas em estudos anteriores para aplicação da celulose na produção cerâmica. A realização de testes após o produto final é encontrada em grande variedade de trabalhos, desde testes de propriedade mecânica, até a análise da difração de raios X do material. Quanto à proporção e tipo de materiais utilizados, foram encontrados trabalhos que empregavam a celulose kraft, e também o resíduo de celulose branca de fibra curta (RIBEIRO, 2010; PINHEIRO, 2008).

Ribeiro (2010) preparou compósitos com 10, 20 e 40\% de resíduo de celulose em matriz de argila vermelha e realizou testes de absorção de água, massa específica aparente, porosidade, resistência mecânica, retração linear na queima, difração de raios $X$, análise térmica diferencial, microscopia eletrônica de varredura e ensaio de solubilização. O resultado dos ensaios mecânicos mostra que uma adição de até $10 \%$ de celulose o material final possui melhor qualidade quanto a tensão de ruptura à flexão, mas com redução da propriedade quando se adiciona $20 \%$. No teste de absorção de água o melhor resultado também foi obtido 
com $10 \%$ de celulose, apresentando uma absorção de água $19 \%$ menor que o material puro de argila. O resultado obtido foi de que uma adição de $10 \%$ de resíduo de celulose na cerâmica é vantajosa, porém os aumentos com $20 \%$ e $40 \%$ de celulose tornam o material menos resistente.

Já Pinheiro e colaboradores (2008) utilizaram resíduo composto predominantemente por calcita, celulose e caulinita, e argila vermelha para produção de cerâmica vermelha. Neste caso, os valores adicionados de resíduo a argila foram de 3, 5, 10\% e comparados com a matéria prima pura. As propriedades físicas e mecânicas testadas foram: retração linear na queima, tensão de ruptura à flexão e absorção de água. $\mathrm{O}$ resultado obtido para absorção de água mostrou que o aumento da concentração de celulose eleva o percentual de absorção de água. $\mathrm{O}$ teste de tensão de ruptura à flexão apresentou uma melhoria na resistência para a cerâmica com adição de 3\% de resíduo de celulose, decaindo quando se utilizou 5\% e 10\%, respectivamente. Por fim a adição de $3 \%$ se mostrou mais vantajosa, pois quando maiores quantidades de celulose são utilizadas há prejuízos nas propriedades.

\section{METODOLOGIA}

Para o desenvolvimento deste trabalho foram utilizados os seguintes materiais: massa moída de argila, utilizada para a produção de pisos cerâmicos, proveniente de Cordeirópolis, e fibra curta de celulose branca, proveniente de Várzea Paulista. Os materiais foram utilizados da forma como foram recebidos, ou seja, sem tratamento prévio.

A composição química da argila, indicada pelo fornecedor, é: $64,45 \% \mathrm{SiO}_{2}, 16,25 \%$ $\mathrm{Al}_{2} \mathrm{O}_{3}, 7,58 \% \mathrm{Fe}_{2} \mathrm{O}_{3}, 2,96 \% \mathrm{~K}_{2} \mathrm{O}$ e o restante é composto por impurezas e materiais com representatividade abaixo de 1\% (PG QUÍMICA, 2017).

A formulação química da celulose é $\left(\mathrm{C}_{6} \mathrm{H}_{10} \mathrm{O}_{5}\right)_{n}$, podendo conter impurezas, as quais não foram informadas pelo fornecedor, com ponto de ignição de $232{ }^{\circ} \mathrm{C}$ (FLOCOSFIBRA, 2014).

As produções dos corpos de prova foram feitas a partir de um molde de aço desenhado para esse procedimento, composto por uma base, uma matriz e uma punção. Foi prensado $200 \mathrm{~g}$ de material a $25 \mathrm{MPa}$ com dimensões de 100 × $50 \mathrm{~mm}$ com altura variada entre 20 e $25 \mathrm{~mm}$. O molde utilizado é mostrado na Figura 3.

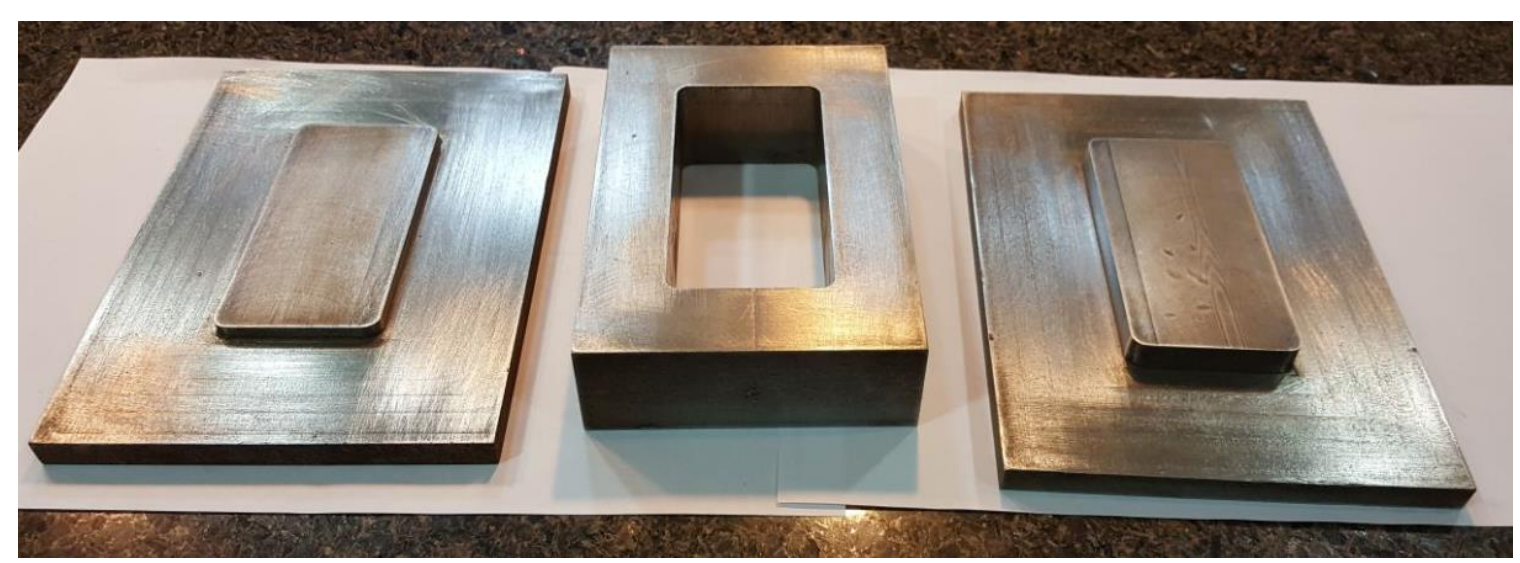

Figura 3 - Fotografia do molde utilizado na produção dos corpos de prova.

Fonte: Arquivo do autor

A prensagem foi realizada em prensa hidráulica, Figura 4, com massa de 4 toneladas. Os corpos de prova, representados na Figura 5, foram submetidos à secagem em estufa de laboratório a $100{ }^{\circ} \mathrm{C}$ por $24 \mathrm{~h}$. 


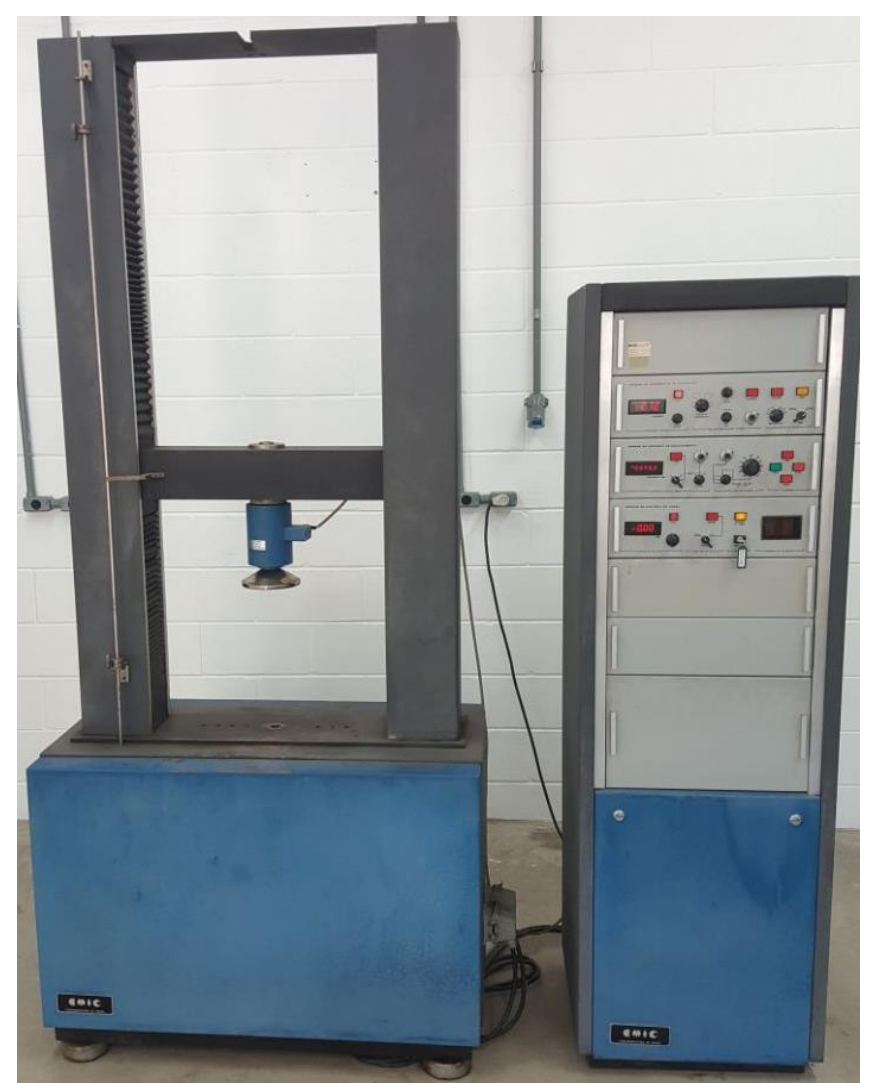

Figura 4 - Fotografia da prensa utilizada para a produção dos corpos de prova. Fonte: Arquivo do autor.

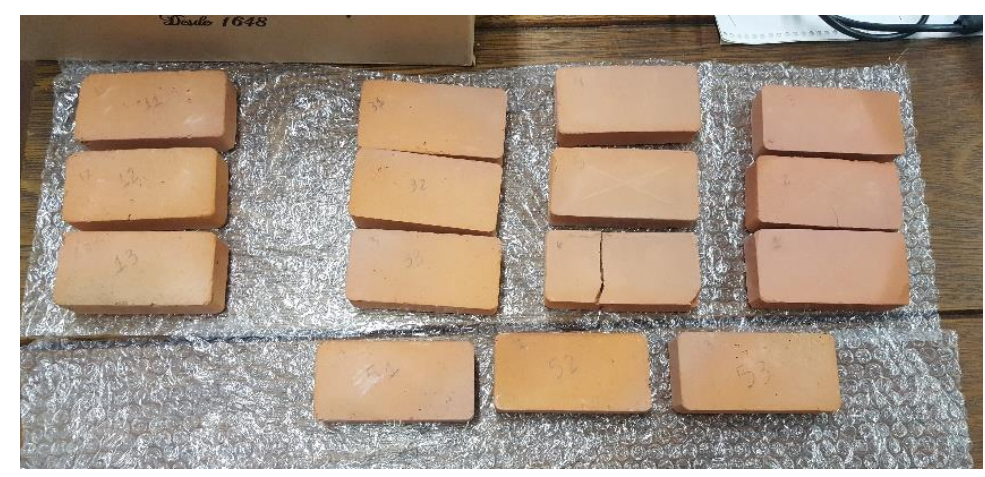

Figura 5 - Fotografia dos corpos de prova após a secagem.

Fonte: Arquivo do autor.

Para o processo de queima foi utilizado o Forno Mufla EDG Equipamentos. O processo foi feito de uma única vez, utilizando 15 corpos de prova, sendo 6 peças de argila pura e 3 peças de cada uma das misturas de argila contendo 3, 5 e $10 \%$ de adição de resíduo de celulose. A taxa de aquecimento foi de $10{ }^{\circ} \mathrm{C}$ por minuto, permanecendo na temperatura máxima de $900{ }^{\circ} \mathrm{C}$ por 60 minutos. $\mathrm{O}$ resfriamento foi realizado através da troca natural de calor com o ambiente.

Diferentes corpos de prova foram submetidos aos mesmos testes: teste de absorção de água, resistência mecânica à flexão e retração linear. Todos os testes foram comparados, analisando-se o desempenho e o comportamento das diferentes quantidades de celulose adicionadas à cerâmica. 
Para a determinação de absorção de água, os corpos de prova foram pesados pós queima e em temperatura ambiente, em seguida submersos em água à temperatura ambiente, permanecendo por 24 horas. Os corpos foram retirados e imediatamente pesados. Com os dados obtidos utilizou-se a equação 1 para o cálculo de absorção (AA), com $\mathrm{P}_{u}$ sendo o peso úmido e $\mathrm{P}_{q}$ o peso pós queima (RIBEIRO, 2010).

$$
A A(\%)=\frac{P_{u}-P_{q}}{P_{q}} \times 100
$$

O teste de resistência mecânica à flexão foi realizado em máquina de ensaio universal Tinius Olsen, pelo ensaio de flexão em três pontos, com uma velocidade de carregamento de $0,5 \mathrm{~mm} / \mathrm{min}$ e célula de carga de $5 \mathrm{kN}$. A Figura 6 mostra a máquina de ensaio utilizada para as medidas de resistência à flexão.

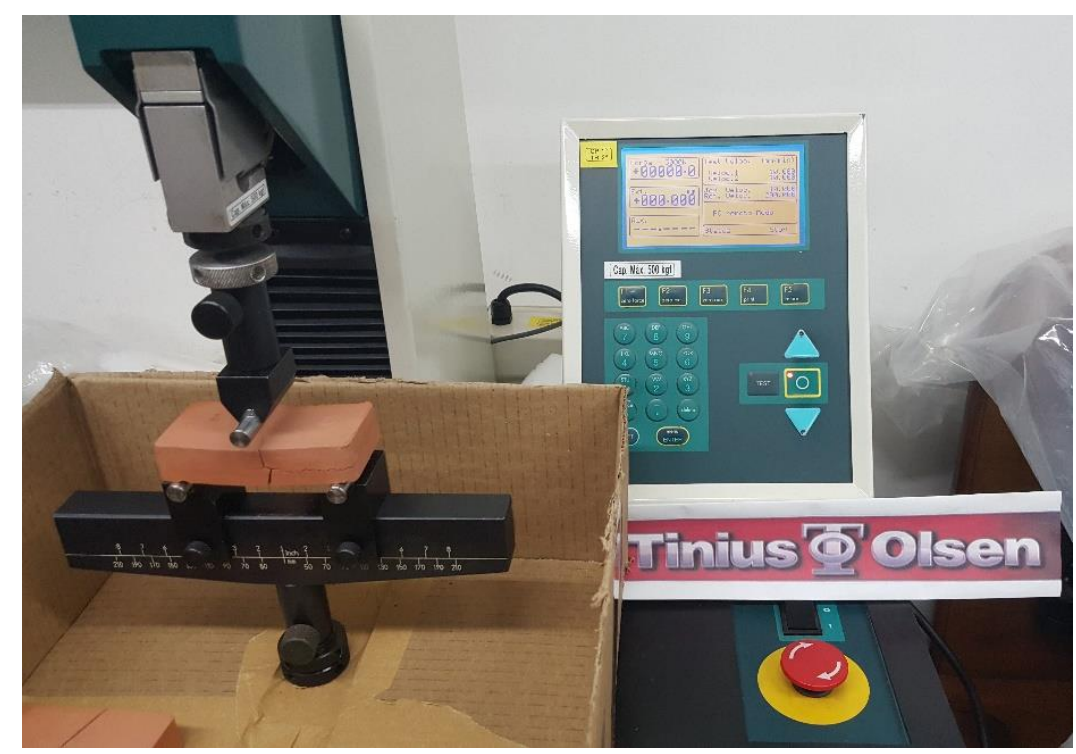

Figura 6 - Fotografia da máquina de ensaio universal Tinius Olsen, utilizada no teste de resistência mecânica à flexão de 3 pontos.

Fonte: própria, equipamento da empresa Dinateste.

A tensão de ruptura à flexão $(T R F)$ foi calculada utilizando a equação 2 , onde $P$ é a força de ruptura $(\mathrm{N}), L$ é a distância entre os apoios $(80 \mathrm{~mm}), b$ é a largura do corpo de prova (mm) e $d$ é a espessura do corpo de prova (mm) (RIBEIRO, 2010).

$$
T R F=\frac{3 \cdot P \cdot L}{2 \cdot b \cdot d^{2}}
$$

As dimensões para o cálculo de retração linear (\%Rt) foram medidas utilizando paquímetro digital com precisão de $0,1 \mathrm{~mm}$. As medições foram realizadas pré e pós queima, e para o cálculo foi utilizado a equação 3 , onde $C_{i}$ é o comprimento pré queima e $C_{q}$ é o comprimento pós queima (RIBEIRO, 2010). 


$$
\% R t=\frac{C_{i}-C_{q}}{C_{i}} \times 100
$$

\section{RESULTADOS E DISCUSSÃO}

Durante a realização desse trabalho esperava-se que as misturas propostas fossem realizadas com destreza e que os resultados fossem satisfatórios. Além disso, pensando no objetivo discutido para o início do artigo, a expectativa era de que com a mistura das fibras curtas de celulose a cerâmica tenham uma melhora no seu desempenho, caracterizando assim, uma possível viabilidade técnica de reciclagem da celulose.

A Figura 7 apresenta o estudo de absorção de água em função da concentração de celulose na cerâmica, a linha traçada horizontalmente, a $22 \%$ de absorção, indica o limite de absorção para blocos cerâmicos estipulados pela ABNT 15270-2 (2005), que diz que o índice de absorção de água não deve ser inferior a $8 \%$ nem superior a $22 \%$ para blocos cerâmicos de alvenaria estrutural.

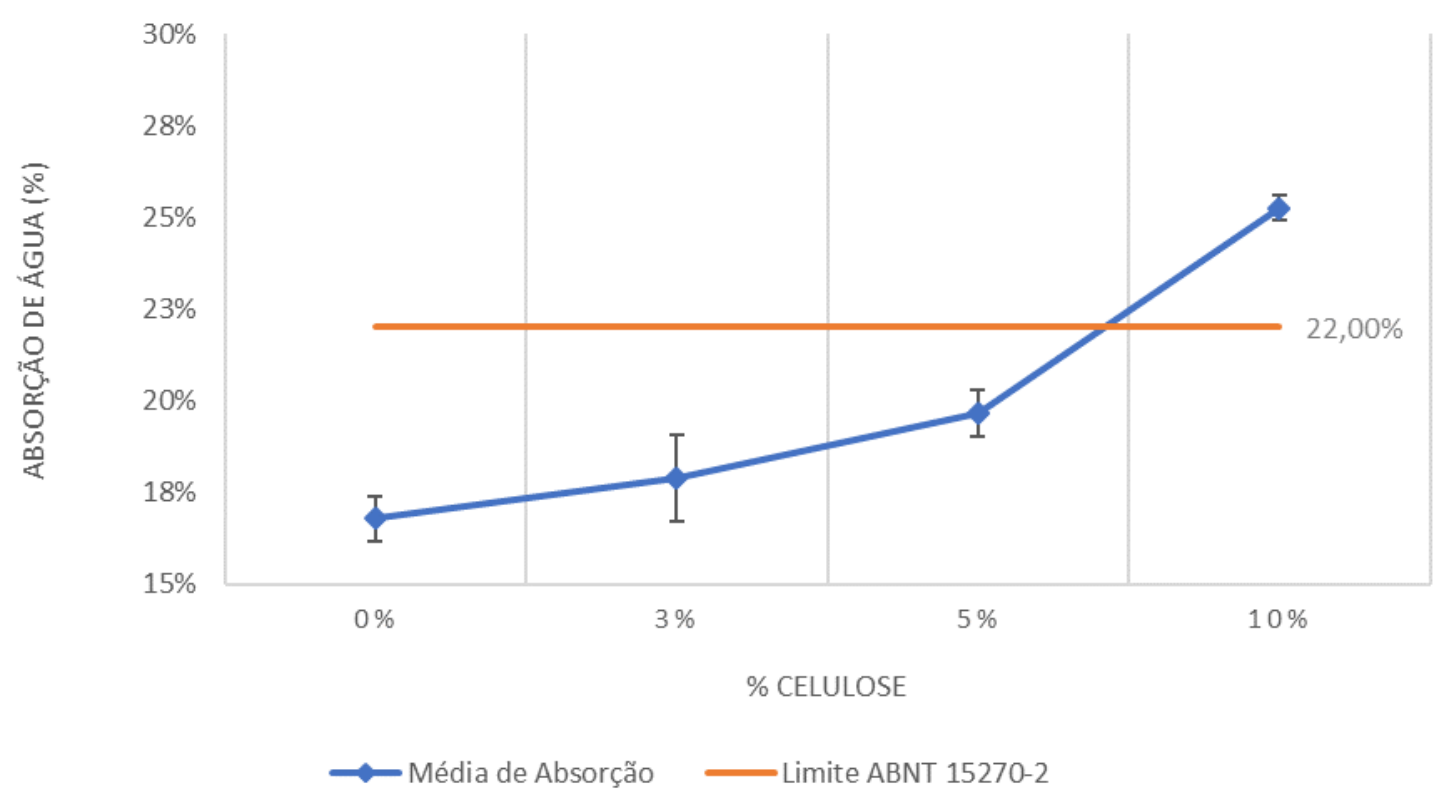

Figura 7 - Absorção de água dos corpos de prova de cerâmica vermelha com celulose com queima realizada a $900^{\circ} \mathrm{C}$.

Como se observa na Figura 7, o estudo de absorção de água mostrou que a mistura com adição de $10 \%$ de celulose possui uma absorção de $25 \%$, valor superior ao limite permitido pela norma ABNT 15270-2 (2005), enquanto que, para as cerâmicas com 3\% e 5\%, apresentaram absorção relativamente próxima ao bloco de argila pura, todos dentro do limite permitido. Esse aumento de absorção provavelmente ocorre devido à queima da celulose adicionada a mistura, tornando o material mais poroso. Tal degradação da celulose se dá a partir dos $232{ }^{\circ} \mathrm{C}$, conforme informações enviadas pelo fornecedor da celulose (FLOCOSFIBRA, 2014).

A Figura 8 apresenta os gráficos de força $v s$. deslocamento oriundos dos ensaios de flexão das amostras, agrupados pelos valores de adição de celulose. 


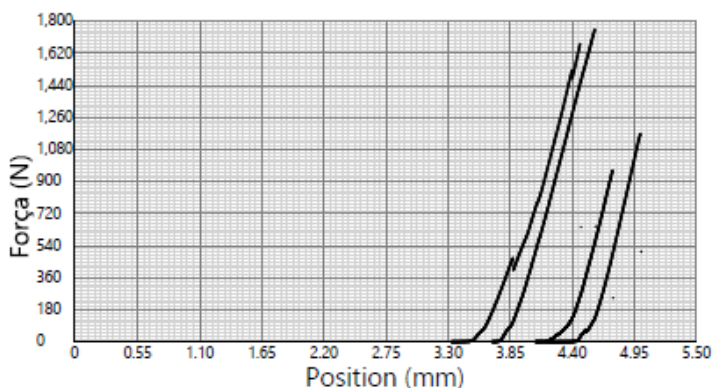

(a)

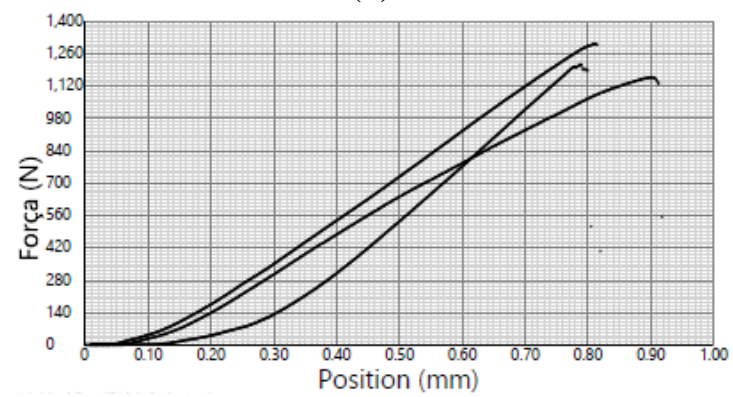

(c)

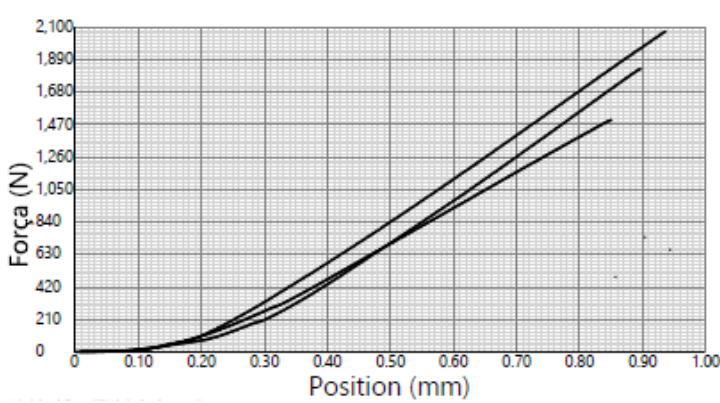

(b)

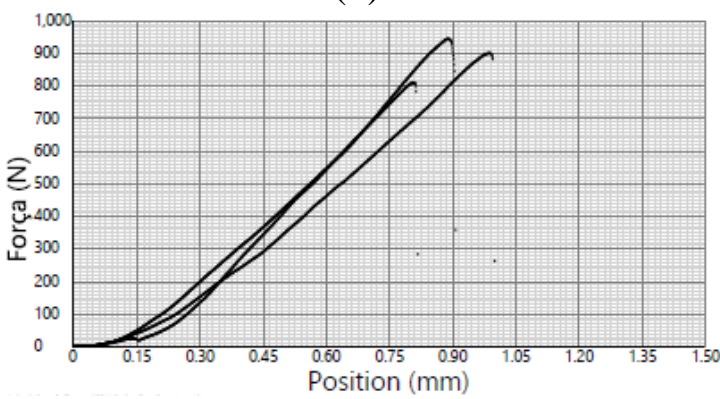

(d)

Figura 8 - Força vs. deslocamento obtidos pelo ensaio de flexão das amostras: (a) $0 \%$ (b) $3 \%$ (c) $5 \%$ (d) $10 \%$.

Observa-se, na Figura 8, que os perfis dos gráficos de força vs. deslocamento são diferentes para a argila com $0,3,5$ e $10 \%$ de concentração de celulose, com os quais é possível verificar os comportamentos, sendo: os blocos de 0 e $3 \%$ apresentam uma ruptura instantânea quando atingida a força de ruptura, já com 5 e 10\%, apresentam uma deformação antes da ruptura total, apresentado nos resultados dos ensaios com uma leve perda de força antes da ruptura. Dessa forma, é possível concluir que a porosidade influencia na resistência mecânica do material, de forma a diminuir sua resistência em função do aumento da concentração de poros, de acordo com o relatado por Callister (2016) para cerâmicas de alumina pura.A Figura 9 apresenta os dados de $T R F$ (tensão de ruptura a flexão) calculados a partir da aplicada da equação 2 .

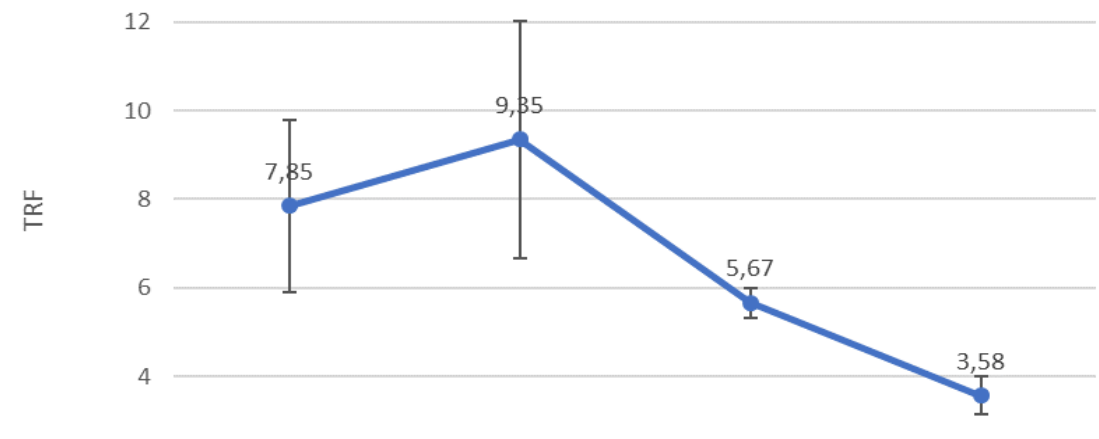

\begin{tabular}{|l|c|c|c|c|}
\multicolumn{1}{c|}{} & \multicolumn{1}{c|}{$0 \%$} & $3 \%$ & $5 \%$ & $10 \%$ \\
\hline \cline { 2 - 5 } \multicolumn{1}{c|}{} & 7,85 & 9,35 & 5,67 & 3,58 \\
\hline Tensão Máx. (Mpa) & 1,95 & 2,67 & 0,34 & 0,42 \\
\hline Desvio Padrão & \multicolumn{2}{|c|}{$\%$ CELULOSE } \\
\hline
\end{tabular}

Figura 9 - Gráfico de tensão de ruptura à flexão da cerâmica vermelha com diferentes concentrações de celulose. 
E possível observar, na Figura 9, que a resistência mecânica à flexão apresentou melhoria com a adição de $3 \%$ de celulose, porém, apresentou menores valores para as adições de $5 \%$ e $10 \%$ de celulose. Isto pode ser explicado pelo aumento do número de poros para maiores concentrações de celulose. De fato, após a ruptura do corpo de prova, foi possível verificar a macroporosidade presente no material com $10 \%$ de celulose, como se pode observar na Figura 10.

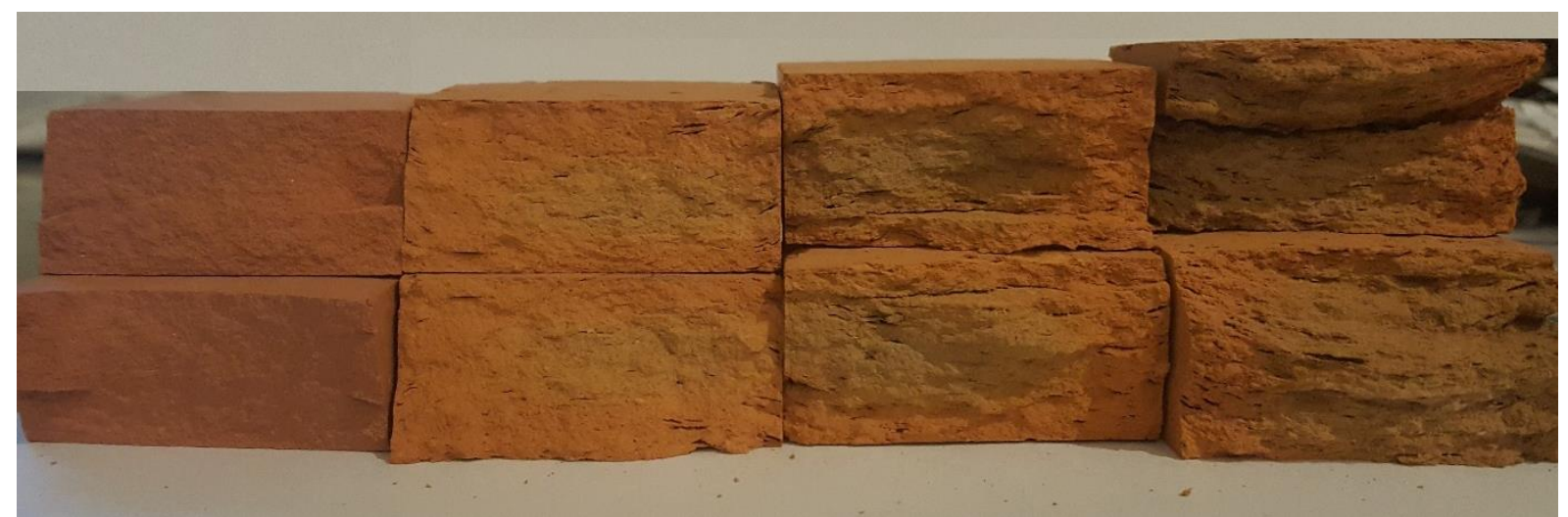

Figura 10 - Macroporosidade aparente das amostras, da esquerda para direita, 0\%, 3\%, 5\%, $10 \%$.

Fonte: Arquivo dos autores.

Os resultados obtidos a partir dos cálculos de retração linear apresentaram valores abaixo de $1 \%$, ou seja, irrisórios. Não foi observada variação da retração em função da quantidade de resíduo adicionada à argila. Esse resultado não influencia o objetivo do trabalho.

Ao comparar os resultados obtidos nesse trabalho com os de Pinheiro e colaboradores (2008), foi possível notar variação de resultados apesar das porcentagens de adição serem iguais. Isso pode ter ocorrido devido à diferença de celulose limpa utilizada neste trabalho para o material lodoso e ao tipo de argila utilizados por Pinheiro (2008). Na Tabela 1 são apresentados os resultados comparativos dos dois trabalhos.

Tabela 1 - Comparação das propriedades obtidas neste trabalho com as do trabalho de Pinheiro e colaborares (2008).

\begin{tabular}{ccccccc}
\hline & \multicolumn{3}{c}{ Este trabalho } & \multicolumn{3}{c}{$\begin{array}{c}\text { Pinheiro e } \\
\text { Colaboradores (2008) }\end{array}$} \\
\cline { 2 - 7 } & $\mathbf{3 \%}$ & $\mathbf{5 \%}$ & $\mathbf{1 0 \%}$ & $\mathbf{3 \%}$ & $\mathbf{5 \%}$ & $\mathbf{1 0 \%}$ \\
\hline $\begin{array}{c}\text { Absorção de Água (\%) } \\
\text { Tensão de Ruptura à Flexão } \\
\text { (MPa) }\end{array}$ & 17,9 & 19,64 & 25,26 & 24 & 26 & 30 \\
Retração Linear (\%) & 9,3 & 5,6 & 3,6 & 3 & 2,1 & 1,8 \\
\hline & & Irrelevante & & 0,81 & 0,85 & 0,82 \\
\hline
\end{tabular}

Na Tabela 1 observa-se que Pinheiro e colaboradores (2008) não se atentaram para a norma ABNT 15270-2 (2005) no que tange ao índice de absorção de água para cerâmicas de alvenaria estrutural. Além disso, os altos índices de absorção de água e os baixos valores de tensão de ruptura à flexão são explicados em função da alta porosidade do material advinda da queima da celulose e da constituição química da argila utilizada, da região de Campos dos Goytacazes, no Rio de Janeiro, que continha altos índices de calcita $\left(\mathrm{CaCO}_{3}\right)$, que se degrada aproximadamente a $840{ }^{\circ} \mathrm{C}$.

Segundo os dados da IBÁ (2016), no ano de 2015 foram reciclados 4,6 milhões de toneladas de papel, representando $61 \%$ de todo material descartado, sendo assim 2,94 milhões (39\%) de toneladas foram descartados sem reaproveitamento. Lembrando os dados do MME 
de que em 2016 foram utilizados 140 milhões de toneladas de argila para a produção de corpos cerâmicos, é possível notar que há espaço para o reaproveitamento total dessa celulose descartada, se adicionada na proporção de 3\% de celulose para a produção de corpos cerâmicos. Dessa maneira, se evitaria o seu descarte na natureza.

\section{CONCLUSÃO}

Com os resultados obtidos nesse trabalho, pode-se concluir que é possível a adição de resíduos de celulose em argila para a produção de cerâmicas, como blocos e tijolos.

Para os testes realizados, uma adição de $3 \%$ de celulose apresentou os resultados mais satisfatórios, com aumento da resistência mecânica sem impactar no índice de absorção de água.

Para o material com 5\% de adição de celulose, os valores de resistência e absorção apresentaram resultados próximos, porém abaixo, do obtido com material puro, portanto, é uma opção possível, porém não a ideal para cerâmicas de alvenaria estrutural.

Quanto à mistura de $10 \%$, o resultado apresenta uma absorção alta e menor resistência mecânica, sendo assim, não se indica esta composição para as aplicações consideradas nesse trabalho.

Com os valores utilizados nesse estudo, concluímos que uma adição de $3 \%$ de celulose a argila apresenta uma melhoria do material final.

Sugere-se para trabalhos futuros o estudo da adição de $1 \%, 2 \%$ e $4 \%$ de resíduo de celulose à argila, afim de melhorar a curva de resistência mecânica.

\section{AGRADECIMENTOS}

Agradecemos à Universidade São Francisco e à Dinateste pela realização dos ensaios práticos deste trabalho.

\section{REFERÊNCIAS}

ABNT 15270-2. Componentes cerâmicos Parte 2: Blocos cerâmicos para alvenaria estrutural - Terminologia e requisitos. 2005.

ANAP, Associação Nacional dos Aparistas de Papel. Relatório estatístico anual, 2015. Disponível em http://www.anap.org.br/anap/wp-content/uploads/2016/09/ANAPRelat\%C3\%B3rio-Anual-2015-2016.pdf. Acessado em: 23 de abr. de 2017.

CALLISTER JR., W. D. Ciência e Engenharia de Materiais: uma Introdução. ed. 9. Rio de Janeiro: LTC, 2016.

FIBRIA, Mídia Release - Fibria encerra 2016 com crescimento de vendas, forte lucro líquido e robusta posição de caixa, 2017. Disponível em <http://www.fibria.com.br/midia/releases/fibria-encerra-2016-com-crescimento-de-vendasforte-lucro-liquido-e-robusta-posicao-de-caixa/> Acessado em: 06 de maio de 2017.

FEAM, Fundação Estadual do Meio Ambiente; FIEMG, Federação das Indústrias do Estado de Minas Gerais. Guia Técnico Ambiental da Indústria de Cerâmica Vermelha, Belo Horizonte, $2013 . \quad$ Disponível em http://www.feam.br/images/stories/producao_sustentavel/GUIAS_TECNICOS_AMBIENTAI S/guia_ceramica.pdf. Acessado em: 25 de abr. de 2017. 
FLOCOSFIBRA INDUSTRIA E COMERCIO LTDA. Ficha de informações de segurança de produtos químicos, 2014. Recebido por <rodrigo@ flocosfibra.com.br> em 30 de out. de 2017.

IBÁ, Indústria Brasileira de Árvores. Relatório Anual. 2016. Disponível em: http://iba.org/images/shared/Biblioteca/IBA_RelatorioAnual2016_.pdf. Acessado em: 27 de maio de 2017.

MME, Ministério de Minas e Energia. Anuário estatístico do setor de transformação de não metálicos, $2017 . \quad$ Disponível em http://www.mme.gov.br/documents/1138775/1732813/ANU\%C3\%81RIO+N\%C3\%83OMETALICOS+2017_27.07.2017.pdf/8a777f0f-3f3c-4f03-85de-8fa783f2813c. Acessado em: 25 de nov. de 2017.

PG QUIMICA. CRC, 2017 [Caracterização de matérias-primas]. Relatório recebido por <gugu@pgquimica.com.br> em 07 de set. de 2017.

PINHEIRO, R.M.; VIEIRA, C.M.F.; RODRIGUEZ, R.S.; MONTEIRO, S.N. Reciclagem de resíduo proveniente da produção de papel em cerâmica vermelha. Matéria, v. 13, n.1, p. 220 $-227,2008$.

RIBEIRO, A. P. Avaliação do uso de resíduos sólidos inorgânicos da produção de celulose em materiais cerâmicos. São Paulo, 2010. Tese (Doutorado) - Escola politécnica da universidade de São Paulo. [Orientador: Prof. Dr. Samuel Marcio Toffoli]. Disponível em http://www.teses.usp.br/teses/disponiveis/3/3133/tde-17082010-103229/pt-br.php. Acesso em 21 de Março de 2017. 